\title{
An observational study of compliance with the Scandinavian guidelines for management of minimal, mild and moderate head injury
}

\author{
Ben Heskestad ${ }^{1}$, Knut Waterloo ${ }^{2,3^{*}}$, Tor Ingebrigtsen ${ }^{4,5}$, Bertil Romner ${ }^{6}$, Marianne Efskind Harr ${ }^{1}$ and Eirik Helseth ${ }^{1,7}$
}

\begin{abstract}
Background: The Scandinavian guidelines for management of minimal, mild and moderate head injuries were developed to provide safe and cost effective assessment of head injured patients. In a previous study conducted one year after publication and implementation of the guidelines (2003), we showed low compliance, involving over-triage with computed tomography (CT) and hospital admissions. The aim of the present study was to investigate guideline compliance after an educational intervention.
\end{abstract}

Methods: We evaluated guideline compliance in the management of head injured patients referred to the University Hospital of Stavanger, Norway. The findings from the previous study in 2003 were communicated to the hospitals physicians, and a feed-back loop training program for guideline implementation was conducted. All patients managed during the months January through June in the years 2005, 2007 and 2009 were then identified with an electronic search in the hospitals patient administrative database, and the patient files were reviewed. Patients were classified according to the Head Injury Severity Scale, and the management was classified as compliant or not with the guideline.

Results: The 1180 patients were 759 (64\%) males and 421 (36\%) females with a mean age of 31.5 (range 0-97) years. Over all, 738 (63\%) patients were managed in accordance with the guidelines and 442 (37\%) were not. Compliance was not significantly different between minimal (56\%) and mild (59\%) injuries, while most moderate (93\%) injuries were managed in accordance with the guidelines $(p<0.05)$. Noncompliance was caused by overtriage in 362 cases (30\%) and undertriage in 80 (7\%). Guideline compliance was 54\% in 2005, 71\% in 2007, and $64 \%$ in 2009.

Conclusions: This study shows higher guideline compliance after an educational intervention involving feed-back on performance. A substantial number of patients are exposed to over-triage, involving unnecessary radiation from CT examinations, and unnecessary costs from hospital admissions.

Keywords: Head injury, Guidelines, Implementation, Compliance

\section{Background}

Clinical practice guidelines are developed to improve the quality of care by translating the best available scientific evidence into specific recommendations. Recent literature reviews suggests that guideline implementation improve not only the processes of patient care, but also health outcomes $[1,2]$.

\footnotetext{
* Correspondence: knut.waterloo@uit.no

${ }^{2}$ Department of Neurology, University Hospital of North Norway, N-9038

Tromsø, Norway

Full list of author information is available at the end of the article
}

Initial management of mild head injuries is focused on the patient's risk for developing intracranial expansive lesions and early detection of deterioration in patients who initially seemed to have mild head injuries [3]. Studies in Scandinavia and Canada show significant interand intra-hospital variation in routines for assessment of the patient's consciousness level and for the use of radiological examinations [4-6].

The Scandinavian Neurotrauma Committee (SNC) published guidelines for management of minimal, mild and moderate head injured patients in 2000 [7]. In

\section{Biomed Central}


parallel, a number of guidelines and clinical decisionrules, such as the Canadian CT head rule (CCHR), the New Orleans Criteria and the National Institute for Health and Clinical Excellence (NICE) guidelines, were developed [8-10].

The publication of the SNC guidelines was followed by a national implementation process in Norway. A questionnaire based survey directed to departments responsible for head injury management indicated widespread use of the guidelines [11]. Our single-hospital study in 2003 showed compliance with the guidelines in only $51 \%$ of the cases [12]. This result was systematically communicated to the hospitals emergency room physicians repeatedly during the period 2003 to 2008. The present study aimed to investigate whether this intervention improved guideline compliance over time.

\section{Materials and methods Study region and population}

The University Hospital of Stavanger is located in the south-western part of Norway and serves a population of 320 000. The hospital has a small neurosurgical unit, but head injured patients are primarily served by the department of general surgery. The minimal and mild head injuries are almost exclusively assessed and managed by pre registration house officers or senior house officers. A computed tomography (CT) scanner is available on a 24-hour basis.

An electronic search in the hospitals patient administrative database identified 1180 patients with minimal, mild or moderate head injury (ICD-10 codes S00 through S09 with subgroups) referred to the hospital during the months January through June in the years 2005, 2007 and 2009. Patients were classified according to the Head Injury Severity Scale [13]. Patients with severe head injury (GCS score 3-8) were not included. The patient files were reviewed retrospectively, and trauma date, sex, age, Glasgow Coma Scale (GCS) score, use of CT and hospital admission, and the presence of eventual additional risk factors according to the SNC guidelines were registered (anticoagulation, clinical signs of skull fracture, shunt-treated hydrocephalus, multiple injuries, and posttraumatic seizures).

\section{Scandinavian guidelines for management of mild head injuries}

The guideline was developed by the Scandinavian Neurotrauma Committee $(\mathrm{SNC})$ and provides an evidencebased decision-making algorithm for management of minimal, mild and moderate head injuries (Figure 1.) [7]. For minimal head injuries, the guidelines recommend return to home without $\mathrm{CT}$ examination, unless additional risk factors are present. Patients with mild head injuries should undergo CT and return to home if the examination is normal, unless additional risk factors are present. For moderate injuries, CT and hospital admission should be provided.

\section{Implementation of the guidelines}

The implementation of the guidelines in Norway included a secondary publication in the Journal of The Norwegian Medical Association which is distributed to $94 \%$ of the doctors in Norway. The guidelines were presented at the annual meeting of the Norwegian Society for Surgery in 2001 and the Trauma Care 2002 Congress in Stavanger. The guidelines are also regularly presented at annual mandatory courses in neurotrauma management for trainees in general and orthopedic surgery and during teaching of medical students in the four medical schools in Norway since 2001.

At Stavanger University Hospital, the guidelines were administratively implemented in 2001. The implementation process at the hospital included repeated lectures held every six months by consultant neurosurgeons and inclusion of the guidelines in the hospitals trauma manual.

\section{Intervention}

Our study of physicians' guideline compliance from 2003 demonstrated a relatively low compliance with only $51 \%$ [12]. A substantial over triage with unnecessary CT examinations and hospital admissions generated unnecessary and inappropriate increases in cost of care, not poor patient outcomes. The publication, implementation and local announcement of the results is considered as an intervention in terms of a feed-back loop mechanism regarding improvement of physicians' guideline compliance.

\section{Classification of guideline compliance}

The management of each single patient was classified as compliant with the guideline or not. Classification as compliant required correct use of CT and/or hospital admission in accordance with the guideline. The management was classified as non-compliant in cases of over-triage (unnecessary use of CT and/or admission) or under-triage (recommended CT examination and/or admission not performed).

\section{Statistics}

We used SPSS for Windows (release 18.0; SPSS Inc., Chicago, IL) for statistical analyses. Comparisons of proportions were done with the chi-squared test. P-values < 0.05 were considered statistically significant.

\section{Results}

The 1180 patients were 759 (64\%) males and 421 (36\%) females with a mean age of 31.5 (range 0-99) years. The 


\section{Minimal, mild and moderate head injuries}

No additional risk factor (table 3) present *

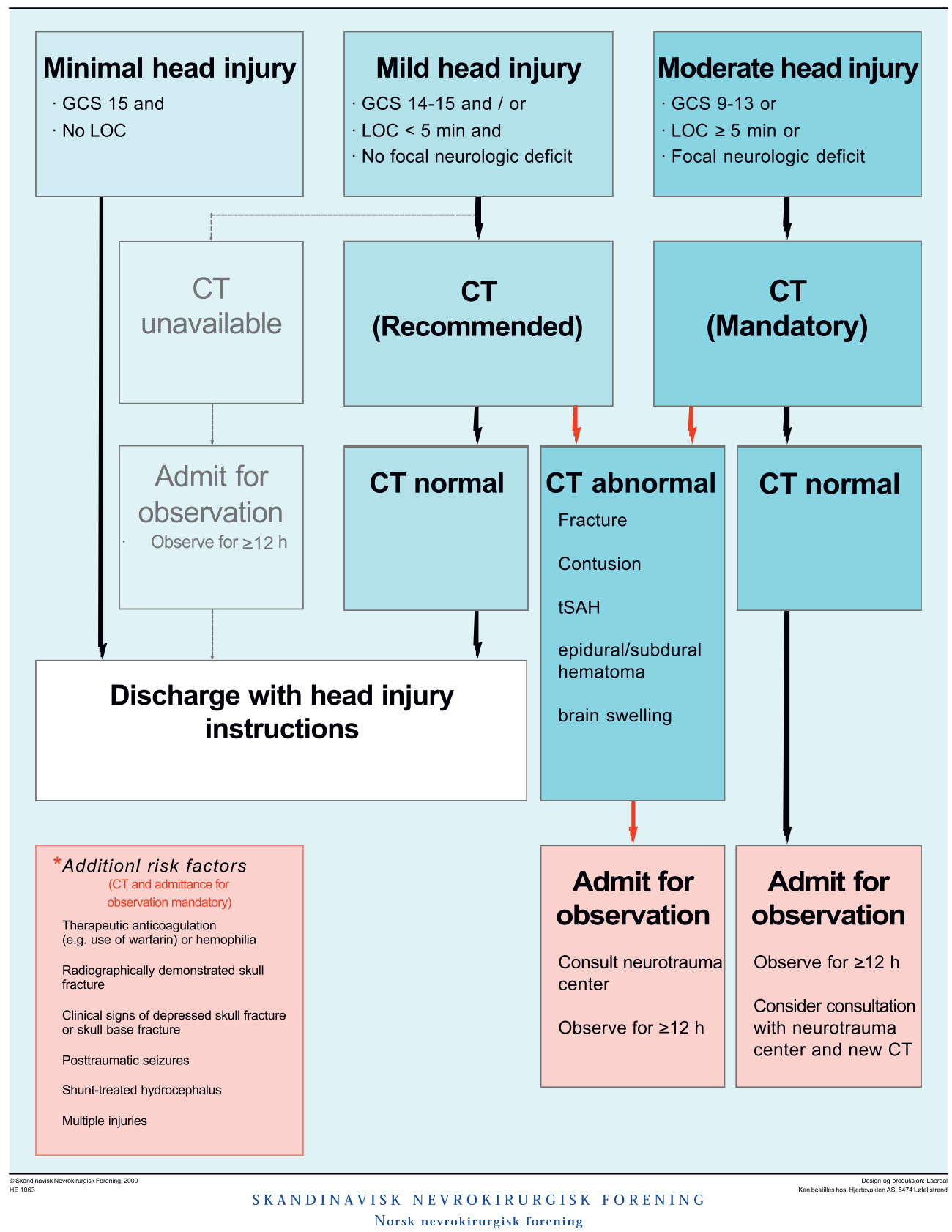

Figure 1 Decision making algorithm for the management of minimal, mild and moderate head injuries recommended by the Scandinavian Neurotrauma Committee [7].

HISS classified 217(18\%) patients with minimal, $806(68 \%)$ with mild and $157(13 \%)$ patients with moderate injuries.

Table 1 show that $738(63 \%)$ patients were managed in accordance with the guidelines, while 442 (37\%) were not. Overall guideline compliance was 54\% in 2005, 71\% in 2007, and 64\% in 2009 (Figure 2). The compliance was not significantly different between minimal (56\%) and mild (59\%) injuries, while most moderate (93\%) injuries were managed in accordance with the guidelines $(\mathrm{p}<0.05)$. 
Table 1 Compliance with the Scandinavian Guidelines for Minimal, Mild and Moderate Head Injuries in 2005, 2007 and 2009

\begin{tabular}{|c|c|c|c|c|c|c|c|c|c|c|c|c|}
\hline \multirow{3}{*}{$\begin{array}{l}\text { Head Injury Severity Scale } \\
\text { classification }\end{array}$} & \multicolumn{3}{|c|}{2005} & \multicolumn{3}{|c|}{2007} & \multicolumn{3}{|c|}{2009} & \multicolumn{3}{|c|}{ Total } \\
\hline & \multirow[t]{2}{*}{$\begin{array}{l}\text { Compliant } \\
(\mathrm{n}=229)\end{array}$} & \multicolumn{2}{|c|}{$\begin{array}{l}\text { Non-compliant } \\
(n=192)\end{array}$} & \multirow[t]{2}{*}{$\begin{array}{l}\text { Compliant } \\
(n=254)\end{array}$} & \multicolumn{2}{|c|}{$\begin{array}{c}\text { Non-compliant } \\
(n=104)\end{array}$} & \multirow[t]{2}{*}{$\begin{array}{l}\text { Compliant } \\
(n=255)\end{array}$} & \multicolumn{2}{|c|}{$\begin{array}{l}\text { Non-compliant } \\
\quad(n=145)\end{array}$} & \multirow[t]{2}{*}{$\begin{array}{l}\text { Compliant } \\
(\mathrm{n}=738)\end{array}$} & \multicolumn{2}{|c|}{$\begin{array}{l}\text { Non-compliant } \\
(n=442)\end{array}$} \\
\hline & & $\begin{array}{l}\text { Overtriage } \\
(n=167)\end{array}$ & $\begin{array}{l}\text { Undertriage } \\
\qquad(\mathrm{n}=25)\end{array}$ & & $\begin{array}{l}\text { Overtriage } \\
(\mathrm{n}=86)\end{array}$ & $\begin{array}{l}\text { Undertriage } \\
\qquad(\mathrm{n}=18)\end{array}$ & & $\begin{array}{l}\text { Overtriage } \\
(n=108)\end{array}$ & $\begin{array}{l}\text { Undertriag } \\
(\mathrm{n}=37)\end{array}$ & & $\begin{array}{l}\text { Overtriage } \\
(n=362)\end{array}$ & $\begin{array}{l}\text { Undertriage } \\
(\mathrm{n}=80)\end{array}$ \\
\hline $\begin{array}{l}\text { Minimal HI } \\
(n=217)\end{array}$ & 45 (48\%) & 46 (50\%) & $1(1 \%)$ & 29 (57\%) & $21(41 \%)$ & $1(2 \%)$ & $46(63 \%)$ & 27 (36\%) & $1(1 \%)$ & $120(56 \%)$ & 94 (43\%) & $3(1 \%)$ \\
\hline $\begin{array}{l}\text { Mild HI } \\
(n=806)\end{array}$ & 137 (49\%) & 122 (44\%) & $19(7 \%)$ & 171 (68\%) & 65 (26\%) & $14(6 \%)$ & 164 (59\%) & 81 (29\%) & 33 (12\%) & 472 (59\%) & 268 (33\%) & $66(8 \%)$ \\
\hline $\begin{array}{l}\text { Moderate HI } \\
(\mathrm{n}=157)\end{array}$ & 47 (90\%) & $0(0 \%)$ & $5(10 \%)$ & 54 (95\%) & $0(0 \%)$ & $3(5 \%)$ & 45 (94\%) & $0(0 \%)$ & $3(6 \%)$ & 146 (93\%) & $0(0 \%)$ & $11(7 \%)$ \\
\hline $\begin{array}{l}\text { Total } \\
(n=1180)\end{array}$ & 229 (54\%) & 167 (39\%) & $25(5 \%)$ & 254 (71\%) & 86 (24\%) & $18(5 \%)$ & 255 (64\%) & $108(27 \%)$ & $37(9 \%)$ & 738 (63\%) & 362 (30\%) & $80(7 \%)$ \\
\hline
\end{tabular}




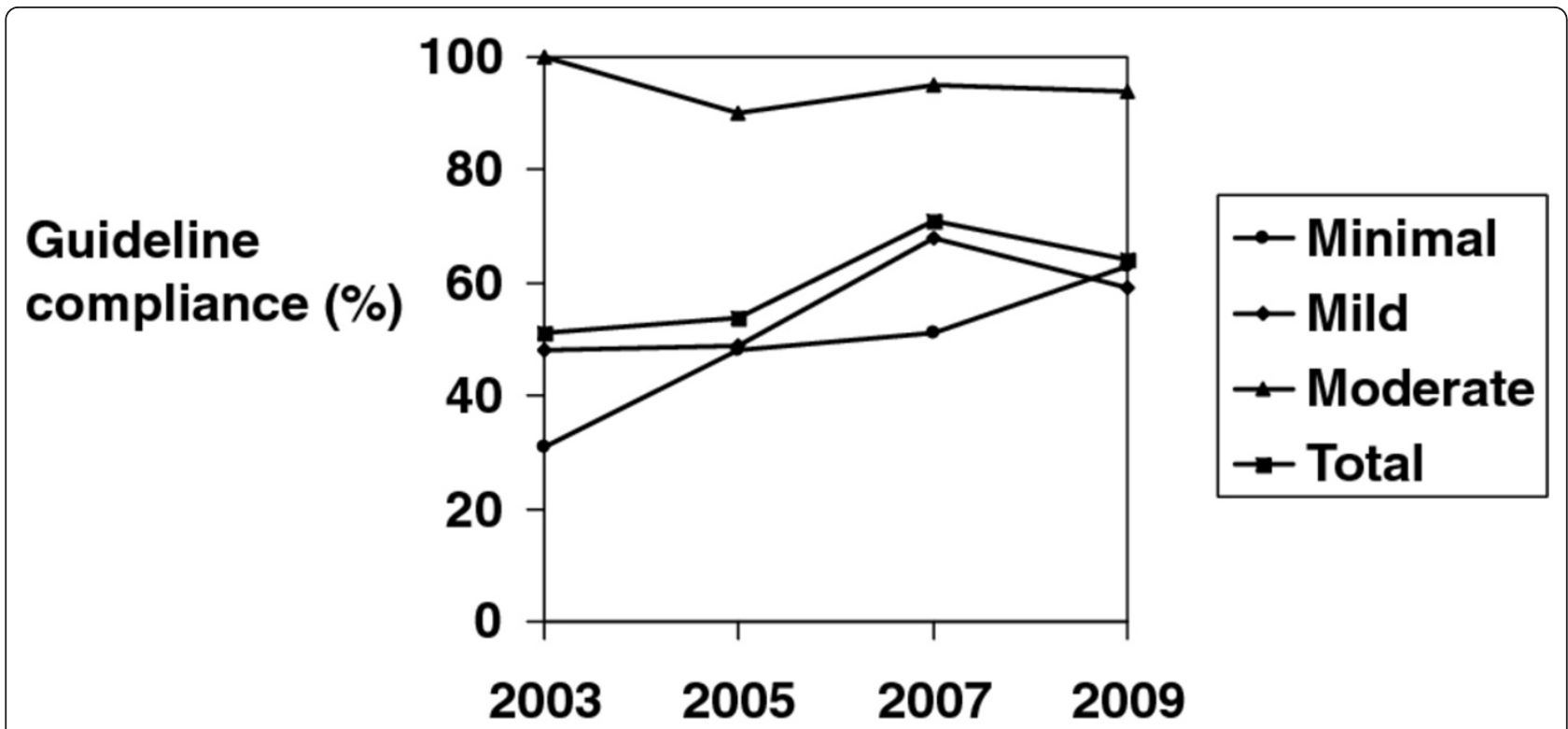

Figure 2 The figure shows compliance with the Scandinavian guidelines for minimal, mild and moderate head injuries in the study years 2005, 2007 and 2009. Observations from a previous study conducted in 2003 are included as a reference [12].

Noncompliance was caused by overtriage in 362 cases (30\%) and undertriage in 80 (7\%). In the minimal and moderate groups, noncompliance was almost exclusively caused by over- and under triage, respectively. Among patients classified with mild injuries, most (33\%) noncompliant management was caused by over triage, but under triage also occurred in a substantial number of patients (8\%). High guideline compliance in 2007 and 2009 was associated with lower over triage among patients classified with mild injuries (Table 1). The over triage caused 108 unnecessary CT examinations and 271 unnecessary hospital admissions among the 1080 patients. Sixty nine patients did not undergo recommended CT and/or hospital admission.

\section{Discussion}

This study was done after an educational intervention in 2004 aiming to improve compliance with The Scandinavian guidelines for management of minimal, mild and moderate head injuries in a Norwegian hospital. We observed an overall guideline compliance of $54 \%$ in 2005 and $64 \%$ in 2009. This is higher than the 51\% reported in a previous study from the same hospital in 2003 [12]. The difference was caused mainly by lower over triage in the present study. It is disappointing that a substantial proportion (36\%) of the patients continue to receive management not in compliance with guidelines. They are exposed to radiation from unnecessary CT-examinations, and the hospital is overspending sparse resources.
The major strengths of the present study were registration of guideline compliance at multiple time points, and at the level of each single patient, in one institution. This ensures reliable information on how patients were managed. The method does not allow generalization to other hospitals. Taking the major implementation efforts at Stavanger University Hospital into consideration, we find it unlikely that compliance rates would be higher at other hospitals. It is a weakness that the study design did not identify the underlying time trend. A statistical interrupted time series analysis could therefore not be done [14]. Clear conclusions on possible causal relations between the educational interventions and the time trend can therefore not be made. Further, it would have been of interest to analyse whether guideline compliance influenced patients' outcomes, especially with regard to intracranial complications. We do not report such data because the number of patients included is insufficient for such analysis.

The most accepted guidelines for management of minor head injuries include the Canadian CT head rule, the New Orleans criteria and the NICE-recommendations [8-10]. To our knowledge, only one study on compliance with these guidelines has been published [15]. This study demonstrated that after the implementation of NICE 2007 guidelines, a significant increase in compliance was observed for adult head injury patients. Few reports on head and brain injury guideline compliance have been reported. In a questionnaire based survey of compliance with the Brain Trauma Foundations 
guidelines for management of severe traumatic brain injury in the US, Hesdorffer and co-workers [16] reported a noncompliance rate of $35 \%$. This represented an improvement from a non-compliance rate of $67 \%$ reported in a previous study from the same authors [17]. We suspect that the compliance rates would have been even lower if observations had been done on the level of single patients, as in the present study. Rusnak and co-workers [18] studied the use of the same guidelines in individual patients treated at five Austrian hospitals, and found that the proportion of patients being managed according to the different recommendations in the guidelines varied from 30 to $89 \%$. Our studies show higher guideline compliance in 2009 than in 2003, but still 1 out of 3 patients are still not managed as recommended.

Advanced trauma life support (ATLS) principles are implemented at the hospital. These recommend a more extended use of CT and hospital admission in case of head injury. Interference between The Scandinavian guidelines and ATLS may be a significant contributor to overtriage. ATLS recommend hospitalization for head injured patients with GCS score 15 if there are significant other injuries or no companion at home. Our study shows that such patients are often also examined with CT. In our opinion, a reconsideration of the ATLS recommendations for head injured patients with GCS score 15 would be reasonable.

A recent study from the Nordic radiation protection cooperation reports concern about increased use of CT [19]. The use has increased gradually from about 50 examinations per 1000 population per year in 1992 to between 60 (Finland), 82 (Denmark), 85 (Sweden), 145 (Iceland) and 195 (Norway) in 2008. The present study indicates that over-triage of head injured patients contribute to the increasing use of CT. Improved guideline implementation strategies and possibly re-evaluation of the applicability of the guidelines are therefore necessary.

Challenges with guideline implementation and adherence are well known problems across health care systems worldwide. A recent study by Flanagan and co-workers [20] differentiate between provider- and workflow-focused implementation strategies, and conclude that a combination of the two improve guideline compliance. We have used a provider focused approach, and possibly reached the highest possible result from this strategy. The findings from Flanagan and co-workers suggest that workflowfocused methods such as computer based reminder systems (tailoring) and redefined roles for physicians and other staff may be necessary to achieve further improvement. A more focused approach, based on analysis of barriers of adhering to individual recommendations may also improve the use and effectiveness of guidelines [21].

\section{Conclusions}

This single center study shows that the compliance with the SNC guidelines for management of head injuries was $51 \%$ in 2003 and $64 \%$ in 2009 , probably as a result from educational interventions involving feed-back on performance. A substantial number of patients are exposed to overtriage, involving unnecessary radiation from CT examinations, and unnecessary costs from hospital admissions. Future studies should focus on identification and analyses of barriers to guideline adherence.

\section{Author details}

'Department of Neurosurgery, Oslo University Hospital - Ullevål, P.O. Box 4950, Nydalen N-0424, Oslo, Norway. ${ }^{2}$ Department of Neurology, University Hospital of North Norway, N-9038 Troms $\varnothing$, Norway. ${ }^{3}$ Department of Psychology, Faculty of Health Sciences, University of Troms $\varnothing, N-9037$ Troms $\varnothing$, Norway. ${ }^{4}$ CEO's office, University Hospital of North Norway, N-9038 Tromsø,

Norway. ${ }^{5}$ Institute for Clinical Medicine, Faculty of Health Sciences, University of Troms $\varnothing, \mathrm{N}-9037$ Troms $\varnothing$, Norway. ${ }^{6}$ Department of Neurosurgery,

Neuroscience Centre, Rigshospitalet, University of Copenhagen, DK-2100 Copenhagen, Denmark. ${ }^{7}$ Faculty of Medicine, University of Oslo, P.O.Box 1018, Blindern N-0315, Oslo, Norway.

\section{Authors' contributions}

$\mathrm{BOH}$ designed the study, acquired and analysed the data, and drafted the manuscript. KW participated in analysis and interpretation of the data and completion of the manuscript. TI contributed to the design of the study and participated in analysis and interpretation of the data and completion of the manuscript. BR participated in analysis and interpretation of the data and completion of the manuscript. MEH participated in acquisition of the data and drafting of the manuscript. EH participated in analysis and interpretation of the data and completion of the manuscript, and participated in designing the study. All authors read and approved the final manuscript.

\section{Competing interests}

Two of the authors (T. I. and B. R.) were involved with the development of The Scandinavian guidelines for management of minimal, mild and moderate head injuries.

Received: 9 October 2011 Accepted: 17 April 2012

Published: 17 April 2012

\section{References}

1. Lugtenberg M, Burgers JS, Westert GP: Effects of evidence-based clinical practice guidelines on quality of care: a systematic review. Qual Saf Health Care 2009, 18:385-392.

2. Farmer AP, Légaré F, Turcot L, Grimshaw J, Harvey E, McGowan JL, Wolf F: Printed educational materials: effects on professional practice and health care outcomes. The Cochrane Library 2009, 4.

3. Klauber MR, Marshall LF, Luerssen TG, Frankowski R, Tabbador K, Eisenberg HM: Determinants of head injury mortality: importance of the low risk patient. Neurosurgey 1989, 24:31-36.

4. Ingebrigtsen T, Romner B: Management of minor head injuries in hospitals in Norway. Acta Neurol Scand 1997, 95:51-55.

5. Bellner J, Ingebrigtsen T, Romner B: Survey of the management of patients with minor head injuries in hospitals in Sweden. Acta Neurol Scand 1999, 100:355-359.

6. Stiell IG, Wells GA, Vandemheen K, Laupacis A, Brison R, Eisenhauer MA, Greenberg GH, MacPhail I, McKnight RD, Reardon M, Verbeek R, Worthington J, Lesiuk H: Variation in ED use of computered tomography for patients with minor head injury. Ann Emerg Med 1997, 30:14-22.

7. Ingebrigtsen T, Romner B, Kock-Jensen C: Scandinavian guidelines for initial management of minimal, mild and moderate head injuries. J Trauma 2000, 48:760-766.

8. Stiell IG, Wells GA, Vandemheen $\mathrm{K}$, Clement $\mathrm{C}$, Lesiuk $\mathrm{H}$, Laupacis $\mathrm{A}$, McKnight RD, Verbeek R, Brison R, Cass D, Eisenhauer ME, Greenberg G, 
Worthington J: The Canadian CT Head Rule for patients with minor head injury. Lancet 2001, 357:1391-1396.

9. Haydel MJ, Preston CA, Mills TJ, Luber S, Blaudeu E, Deblieux PM: Indications for computed tomography in patients with minor head injury. N Engl J Med 2000, 13(343):100-105.

10. National Institute of Health and Clinical Excellence: Head injury: triage, assessment, investigation and early management of head injury in infants, children and adults. NICE Clinical Guideline No 562007 [http:// www.nice.org.uk/CG056].

11. Müller K, Waterloo K, Romner B, Wester K, Ingebrigtsen T: Mild Head injuries: Impact of a national strategy for implementation of management guidelines. J Trauma 2003, 55:1029-1034.

12. Heskestad B, Baardsen R, Helseth E, Ingebrigtsen : Guideline compliance in management of minimal, mild and moderate head injury: high frequency of noncompliance among individual physicians despite strong guideline support from clinical leaders. J Trauma 2008, 65:1309-1313.

13. Stein SC, Spettel C: A practical classification of closed-head injury. Brain Inj 1995, 9:437-444

14. Matowe LK, Leister CA, Crivera C, Korth-Bradley JM: Interrupted time series analysis in clinical research. Ann Pharmacother 2003, 37:1110-6.

15. Mooney JS, Yates A, Sellar L, Shipway T, Roberts C, Parris R, Hassan Z, Thomas M, Smith M, Lecky F: Emergency head injury imaging: implementing NICE 2007 in a tertiary neurosciences centre and a busy district general hospital. Emerg Med J 2011, 28:778-782.

16. Hesdorffer DC, Ghajar J: Marked improvement in adherence to traumatic brain injury guidelines in United States trauma centers. J Trauma 2007, 63:847-8.

17. Hesdorffer DC, Ghajar J, lacono L: Predictors of compliance with the evidence-based guidelines for traumatic brain injury care: a survey of United States trauma centers. J Trauma 2002, 52:1202-9.

18. Rusnak M, Janciak I, Majdan M, Wilbacher I, Mauritz W: Wien Klin Wochenschr 2007, 119:64-71.

19. The Nordic Radiation Protection co-operation: Increased use of CT causes concern in the Nordic countries.[http://www.stralsakerhetsmyndigheten.se/ In-English/About-the-Swedish-Radiation-Safety-Authority1/News1/Increaseduse-of-CT-causes-concern-in-the-Nordic-countries].

20. Flanagan ME, Ramanujam R, Doebbeling BN: The effect of provider- and workflow-focused strategies for guideline implementation on provider acceptance. Implement Sci 2009, 4:71.

21. Lugtenberg M, Zegers-van Schaik JM, Westert GP, Burgers JS: Why don't physicians adhere to guideline recommendations in practice? An analysis of barriers among Dutch general practitioners. Implement Sci 2009, 4:54.

doi:10.1186/1757-7241-20-32

Cite this article as: Heskestad et al: An observational study of compliance with the Scandinavian guidelines for management of minimal, mild and moderate head injury. Scandinavian Journal of Trauma, Resuscitation and Emergency Medicine 2012 20:32.

\section{Submit your next manuscript to BioMed Central and take full advantage of:}

- Convenient online submission

- Thorough peer review

- No space constraints or color figure charges

- Immediate publication on acceptance

- Inclusion in PubMed, CAS, Scopus and Google Scholar

- Research which is freely available for redistribution

Submit your manuscript at www.biomedcentral.com/submit
C Biomed Central 